\title{
Preferential dissolution behaviour in Ni-Cr dental cast alloy
}

\author{
VISWANATHAN S SAJI* and HAN CHEOL CHOE \\ Department of Dental Materials, School of Dentistry, Chosun University, Gwangju 501-759, Korea
}

MS received 11 February 2009; revised 12 April 2009

\begin{abstract}
A Ni-Cr-Mo dental alloy was fabricated by three different casting methods, viz. centrifugal casting, high frequency induction casting and vacuum pressure casting. The dependence of cast microstructure on the electrochemical corrosion behaviour was investigated using potentiodynamic cyclic and potentiostatic polarization techniques, impedance spectroscopy and scanning electron microscopy. The experimental results were compared and discussed with those obtained for a $\mathrm{Co}-\mathrm{Cr}-\mathrm{Mo}$ counterpart. The results of the study showed that the variation in casting morphologies with casting methods has only marginal influence in the overall corrosion resistance of $\mathrm{Ni}-\mathrm{Cr}$ and $\mathrm{Co}-\mathrm{Cr}$ dental alloys. There was severe preferential dissolution of $\mathrm{Ni}$ rich, $\mathrm{Cr}$ and $\mathrm{Mo}$ depleted zones from the $\mathrm{Ni}-\mathrm{Cr}-\mathrm{Mo}$ alloy. The overall corrosion resistance property of the $\mathrm{Co}-\mathrm{Cr}$ base alloy was better than that of the $\mathrm{Ni}-\mathrm{Cr}$ base alloy.
\end{abstract}

Keywords. Ni-Cr-Mo; dental cast alloy; microstructure; corrosion; cyclic polarization.

\section{Introduction}

Co and Ni based alloys are widely used in dental skeletal structures and orthopedic implants such as screws, pins and plates (Wataha 2000). The advantages of these alloys include low cost of casting, matching thermal expansion coefficient with the ceramics of metal-ceramic restorations and acceptable mechanical and tribological properties in vivo (Wataha et al 2001; Schmalz and Garhammer 2002; Joias et al 2008). However, the possible release of toxic metal ions due to corrosion remains a major concern (Wataha et al 2001; Schmalz and Garhammer 2002). The release of $\mathrm{Ni}$ is of particular concern as it is the most allergenic of all metallic elements (Hildebrand et al 1989). In vivo studies have shown that corrosion products of $\mathrm{Ni}-\mathrm{Cr}$ alloys decreased cellular proliferation (Bumgardner and Lucas 1995).

Casting is one of the main methods of producing shaped metals and alloys. Corrosion behaviour of $\mathrm{Ni}-\mathrm{Cr}$ and $\mathrm{Co}-$ $\mathrm{Cr}$ dental cast alloys depends primarily on the $\mathrm{Cr}$ and $\mathrm{Mo}$ levels in the alloy (Roach et al 2000). In commercial alloys, the composition of $\mathrm{Cr}$ and Mo ranges from 11-25 and $0-10 \mathrm{wt} \%$, respectively (Wylie et al 2007). Both the microstructure and casting defects can have pronounced effect on the ion release in actual practice. The defects of dental cast alloys are mainly shrinkage porosity, inclusions, micro cracks and dendritic structure. Few reported works were available on the influence of casting procedures on the corrosion resistance of different dental alloys (Cohen et al 1996; Mulders et al 1996; Viennot et al 2006; Kim et al 2007; Saji et al 2009).

\footnotetext{
*Author for correspondence (vssaji@hotmail.com)
}

In the present work, corrosion behaviour of a $\mathrm{Ni}-\mathrm{Cr}-$ Mo dental alloy was studied as a function of casting method. The results were compared with those obtained for a $\mathrm{Co}-\mathrm{Cr}-\mathrm{Mo}$ alloy. The relationship of the processing induced structure and the passive film homogeneity to the electrochemical behaviour were discussed.

\section{Experimental}

\subsection{Alloy making}

The alloys were prepared for fabricating partial denture frameworks using centrifugal casting (Kerr, USA), vacuum pressure casting (Bego, Germany) and high frequency induction casting (Jelenko Eagle, USA). The casting temperature used was $1380^{\circ} \mathrm{C}$ for both centrifugal and vacuum pressure casting and $1420^{\circ} \mathrm{C}$ for high frequency induction casting. The samples for the study were selected from the runner area of the denture framework. Table 1 represents chemical composition of the alloys. The samples were etched in $2 \mathrm{ml} \mathrm{HF}+3 \mathrm{ml} \mathrm{HCl}+5 \mathrm{ml} \mathrm{HNO}_{3}+190 \mathrm{ml}$ $\mathrm{H}_{2} \mathrm{O}$ solution and the microstructures were analysed using scanning electron microscope (FE-SEM, H-4700, Hitachi, Japan) and energy dispersive spectroscopy (EDS, JXA-8900M, Jeol, Japan).

Table 1. Chemical composition of the alloys (wt\%).

\begin{tabular}{lcccccccc}
\hline Alloy & $\mathrm{Co}$ & $\mathrm{Ni}$ & $\mathrm{Cr}$ & $\mathrm{Mo}$ & $\mathrm{Al}$ & $\mathrm{Be}$ & $\mathrm{Mn}$ & $\mathrm{Fe}$ \\
\hline $\mathrm{Ni}-\mathrm{Cr}$ & 8 & bal. & 16 & 5 & 3 & 1.5 & 3.5 & - \\
$\mathrm{Co}-\mathrm{Cr}$ & bal. & 0.99 & 27 & 5.5 & - & - & - & 2 \\
\hline
\end{tabular}



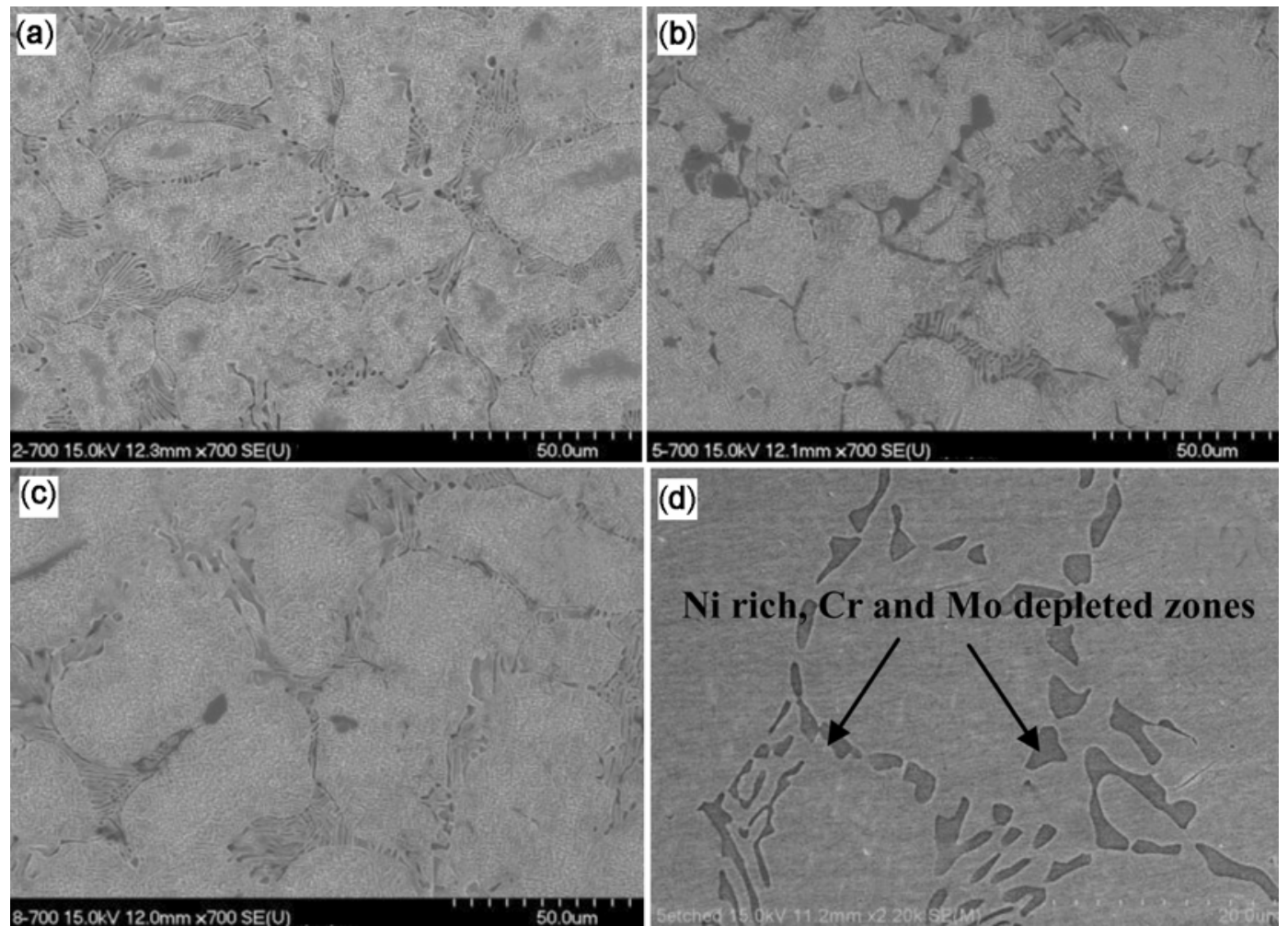

Figure 1. FE-SEM micrographs showing cast structure of Ni-Cr alloy: (a) centrifugal casting, (b) high frequency induction casting, (c) vacuum pressure casting and (d) high magnification image showing $\mathrm{Ni}$ rich zones in centrifugal cast alloy.

\subsection{Electrochemical tests}

Electrochemical corrosion behaviour of the alloys was studied in $0.9 \mathrm{wt} \% \mathrm{NaCl}$ at $37 \pm 1^{\circ} \mathrm{C}$ using a potentiostat/ galvanostat (EG\&G, 263A). Potentiodynamic cyclic polarization and potentiostatic polarization were employed for the purpose. A conventional three-electrode system with high density graphite as counter electrode and saturated calomel electrode (SCE) as reference was used. The sample was mounted in a cold mount epoxy resin. The sample edges were carefully covered with the epoxy to avoid the possible crevice attack. The electrolyte was de-aerated with high purity Ar gas for $1 \mathrm{~h}$ before starting the experiment. De-aeration was continued at a uniform rate during the experiment and the solution was subjected to mild stirring using a magnetic stirrer. The scan rate used for cyclic polarization was $1.667 \mathrm{mV} / \mathrm{s}$. Corrosion current density values $\left(i_{\text {corr }}\right)$ were evaluated by Tafel extrapolation method.

EIS plots at open circuit potential and at $300 \mathrm{mV}$ were recorded using an electrochemical impedance analyser (EIS, EG\&G, 1025). A similar three-electrode set-up as described above was used for EIS studies. The frequency range used for EIS was $10^{-1} \mathrm{~Hz}$ to $10^{5} \mathrm{~Hz}$. The amplitude of A.C. signal was $10 \mathrm{mV}$ and 5 points per decade was used.

\section{Results}

\subsection{Cast microstructure}

Figure 1 represents typical dendritic microstructures obtained for the $\mathrm{Ni}-\mathrm{Cr}$ alloy, fabricated by three different casting methods. The microstructure exhibited two distinct regions in elemental composition; matrix and $\mathrm{Ni}$ rich zone. The composition of the matrix and the Ni rich zone, as determined by EDS, were approximately $68 \mathrm{Ni}-20 \mathrm{Cr}-$ $5 \mathrm{Mo}$ and $92 \mathrm{Ni}-4 \mathrm{Cr}-1 \mathrm{Mo}$ (wt\%), respectively. Figure 2 shows an EDS line analysis of the component elements of the alloy across the nickel rich zone. It can be observed that these regions were poor in all other major component elements of the alloy. Preferential segregation of nickel rich phases occurred during solidification to a larger extent.

\subsection{Electrochemical studies}

Figure 3 represents the potentiodynamic cyclic polarization plots recorded for the $\mathrm{Ni}-\mathrm{Cr}$ alloys, fabricated by three different casting methods. For comparison, the plots obtained for a $\mathrm{Co}-\mathrm{Cr}$ alloy was also given in the same graph. The corresponding corrosion parameters are given in table 2. It is evident that the $\mathrm{Ni}-\mathrm{Cr}$ base alloy exhibited 

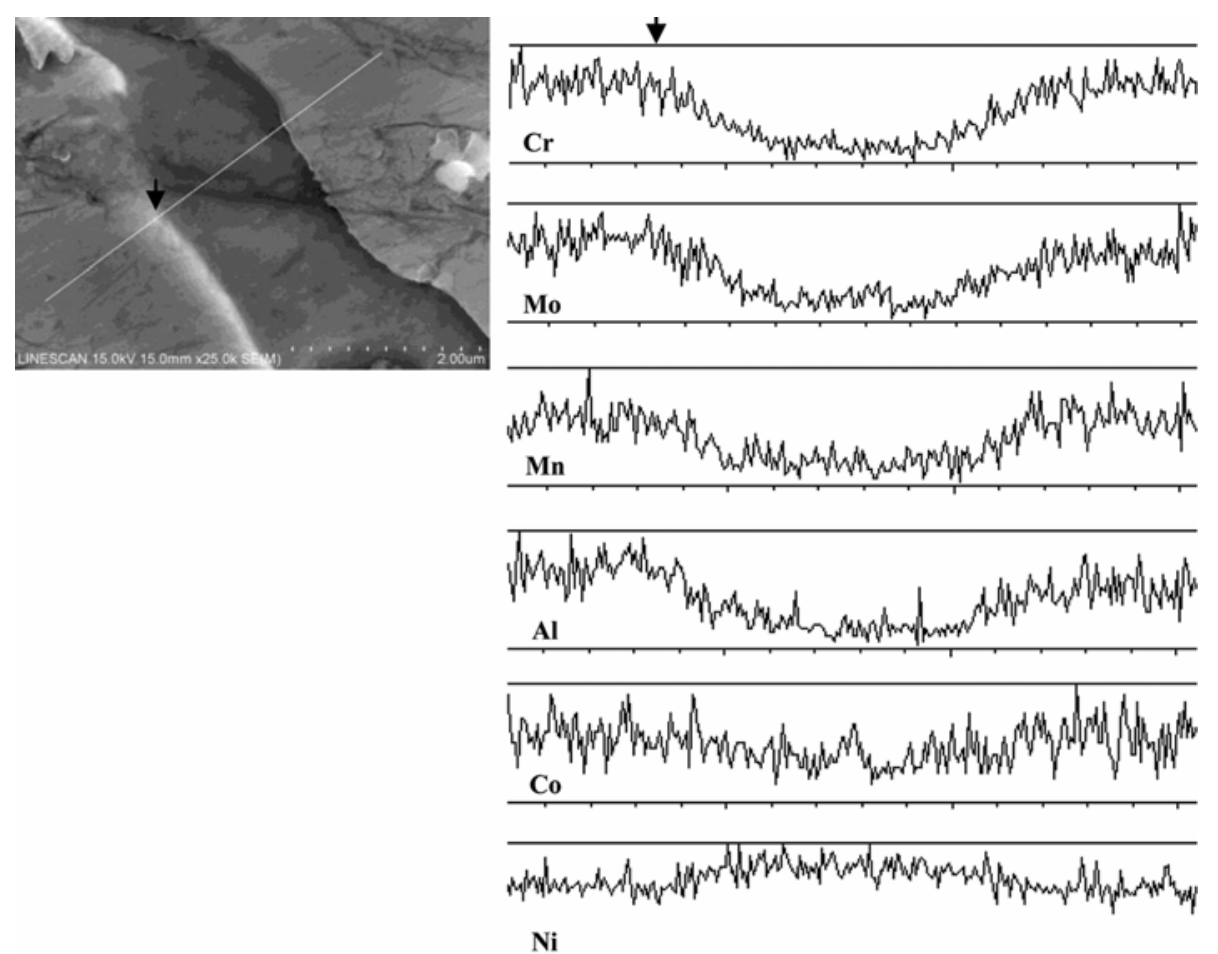

Figure 2. EDS line scan analysis recorded across the nickel rich zone in centrifugal cast alloy

Table 2. Corrosion parameters.

\begin{tabular}{|c|c|c|c|c|c|c|}
\hline \multirow[b]{2}{*}{ Parameter } & \multicolumn{2}{|c|}{ Centrifugal casting } & \multicolumn{2}{|c|}{ High frequency induction casting } & \multicolumn{2}{|c|}{ Vacuum pressure casting } \\
\hline & $\mathrm{Ni}-\mathrm{Cr}$ & $\mathrm{Co}-\mathrm{Cr}$ & $\mathrm{Ni}-\mathrm{Cr}$ & $\mathrm{Co}-\mathrm{Cr}$ & $\mathrm{Ni}-\mathrm{Cr}$ & $\mathrm{Co}-\mathrm{Cr}$ \\
\hline$i_{\text {corr }}\left(\mu \mathrm{Acm}^{-2}\right)$ & $3 \cdot 2$ & 1.4 & $4 \cdot 2$ & $1 \cdot 6$ & $3 \cdot 8$ & $1 \cdot 2$ \\
\hline$E_{\text {corr }}(\mathrm{mV})$ & -410 & -540 & -390 & -520 & -395 & -490 \\
\hline$E_{\text {pit }}(\mathrm{mV})$ & +170 & +630 & +140 & +655 & +135 & +660 \\
\hline
\end{tabular}

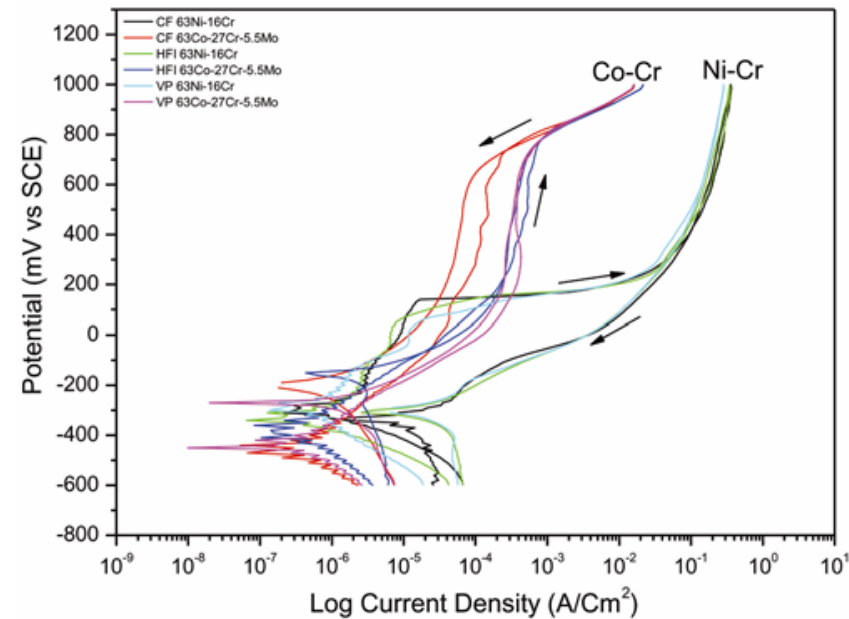

Figure 3. Cyclic potentiodynamic polarization plots of $\mathrm{Ni}-\mathrm{Cr}$ and $\mathrm{Co}-\mathrm{Cr}$ alloys in $0.9 \mathrm{wt} \% \mathrm{NaCl}$ solution at $36.5 \pm 1{ }^{\circ} \mathrm{C}$.

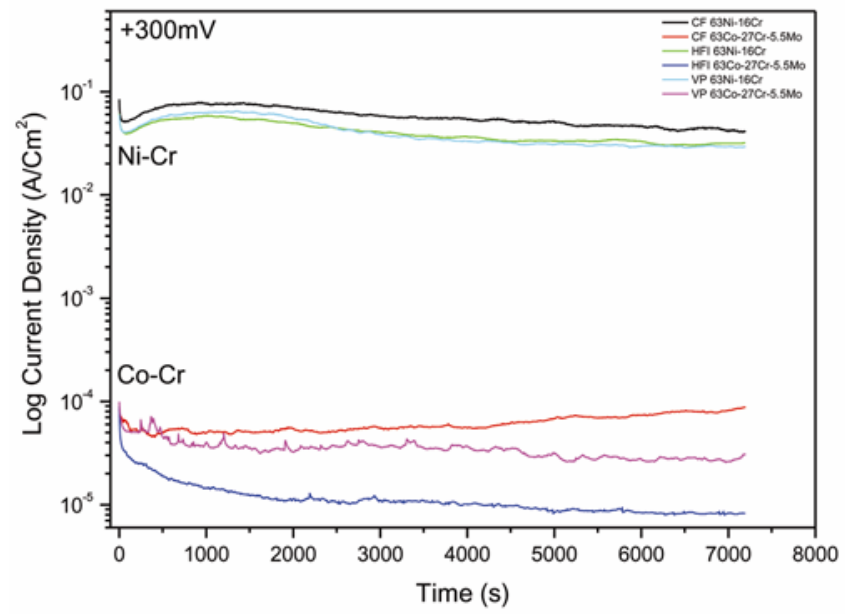

Figure 4. Potentiostatic current-time plots at $300 \mathrm{mV}$ of Ni$\mathrm{Cr}$ and $\mathrm{Co}-\mathrm{Cr}$ alloys in $0.9 \mathrm{wt} \% \mathrm{NaCl}$ solution at $36.5 \pm 1{ }^{\circ} \mathrm{C}$. 

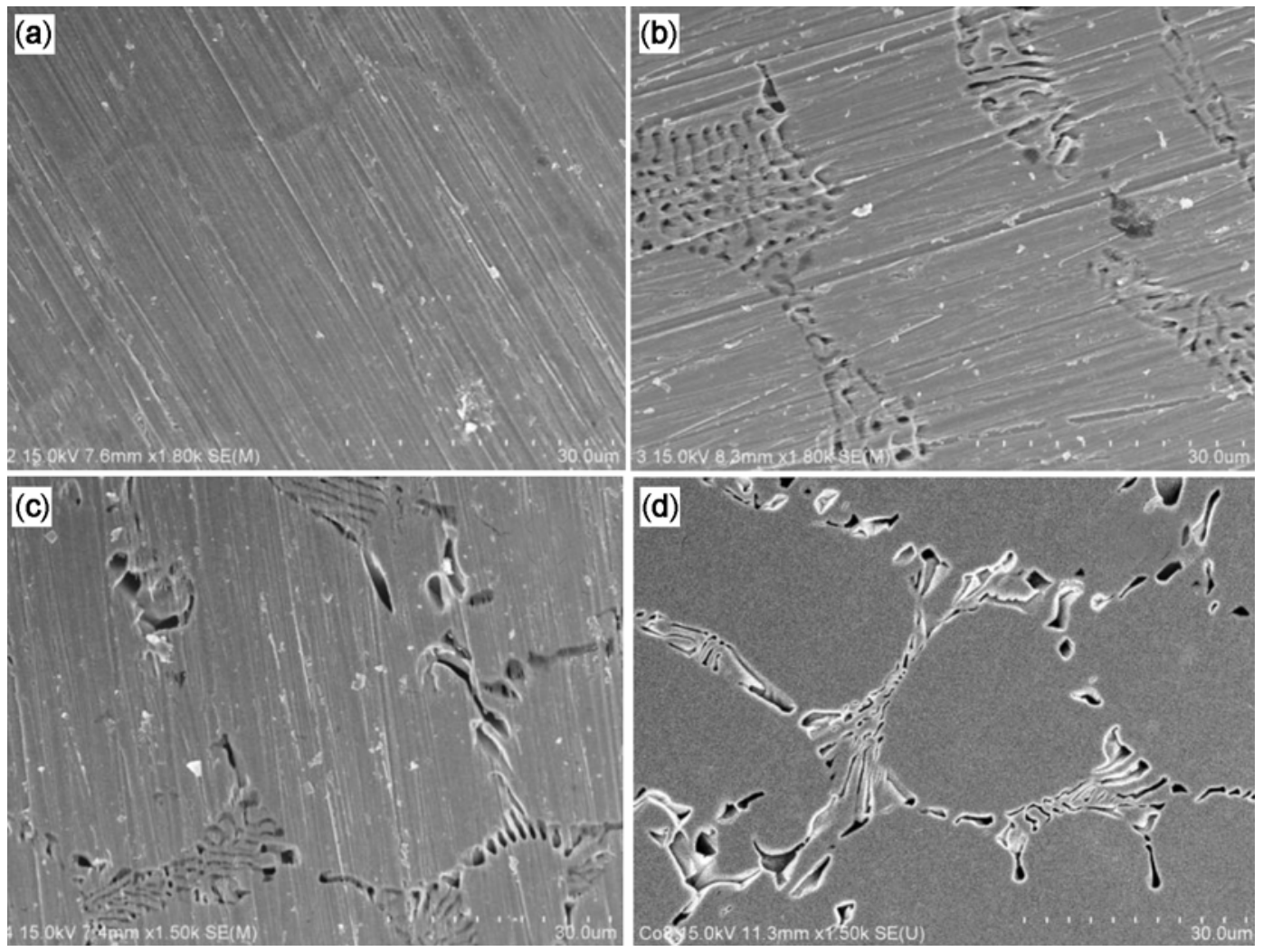

Figure 5. FE-SEM micrographs of high pressure induction cast $\mathrm{Ni}-\mathrm{Cr}$ alloy after potentiodynamic polarization up to different potentials. (a) $50 \mathrm{mV}$, (b) $150 \mathrm{mV}$, (c) $500 \mathrm{mV}$ and (d) $1000 \mathrm{mV}$.

higher corrosion current density values $\left(i_{\text {corr }}\right)$ than the $\mathrm{Co}-\mathrm{Cr}$ base alloy irrespective of the casting method followed. More active pitting $\left(E_{\text {pit }}\right)$ and large negative hysteresis loop obtained for the $\mathrm{Ni}-\mathrm{Cr}$ alloy shows its higher susceptibility to localized corrosion (Rosen and Silverman 1992). The $\mathrm{Co}-\mathrm{Cr}$ alloy exhibited nobler breakdown potential $\left(E_{\mathrm{pit}}\right)$ values with no hysteresis. The negative reverse scan observed for the $\mathrm{Co}-\mathrm{Cr}$ alloy may be associated with the corrosion product formation on the surface, above the breakdown potential. Figure 4 represents the potentiostatic polarization plots recorded at 300 $\mathrm{mV}$ for the two alloys. The larger corrosion current density values indicate higher dissolution rate of the $\mathrm{Ni}-\mathrm{Cr}$ alloy in the electrolyte.

The surfaces of $\mathrm{Ni}-\mathrm{Cr}$ alloys after the potentiodynamic polarization experiments were examined using SEM to identify the sites of corrosion attack. The SEM images of the samples revealed severe localized dissolution. The $\mathrm{Ni}$ rich, $\mathrm{Cr}$ and Mo depleted zones were locally removed from the surface. To understand the potential dependence of the dissolution, we have examined the SEM surface images after potentiodynamically polarizing the $\mathrm{Ni}-\mathrm{Cr}$ alloy up to different potentials, viz. 50, 150, 500 and $1000 \mathrm{mV}$ (figure 5). As evident from the figure, preferential dissolution of the nickel rich zones was prominently seen at $150 \mathrm{mV}$. When the sample was polarized up to $500 \mathrm{mV}$, severe dissolution of the nickel rich zones happened.
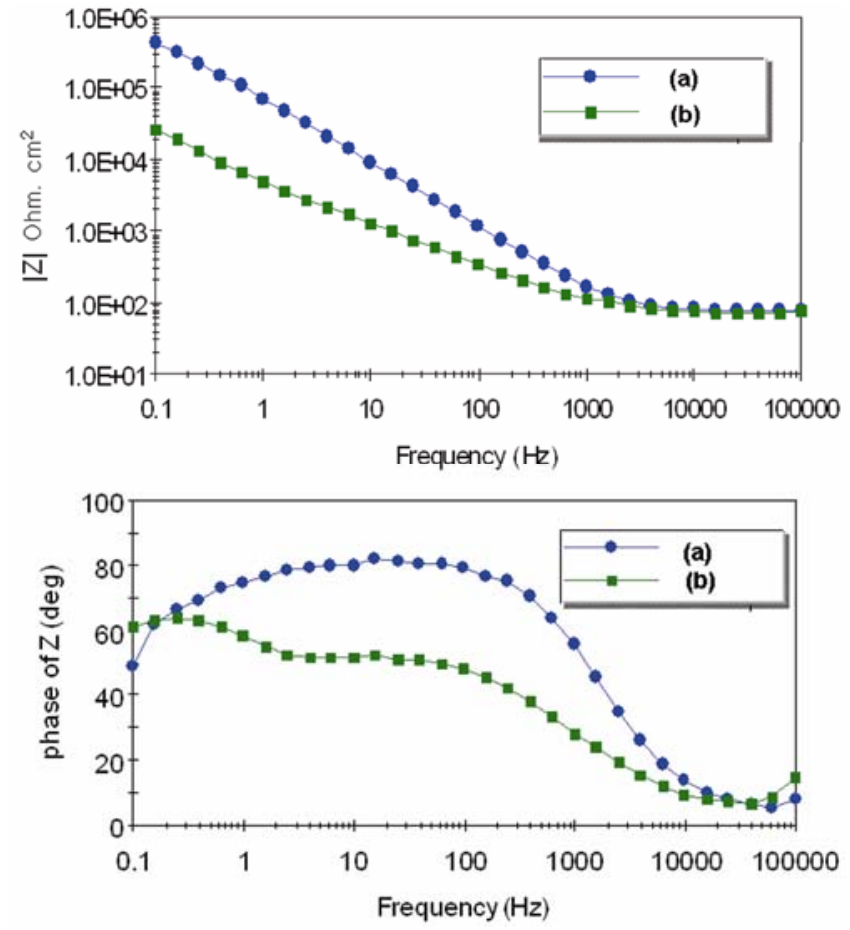

Figure 6. Impedance bode plot recorded for the centrifugally cast $\mathrm{Ni}-\mathrm{Cr}$ alloy at (a) open circuit potential and (b) $300 \mathrm{mV}$

A representative EIS Bode plot recorded for the centrifugal casted $\mathrm{Ni}-\mathrm{Cr}$ alloy at open circuit potential and 
$300 \mathrm{mV}$ is shown in figure $6.300 \mathrm{mV}$ corresponds to maximum potential that occurs in practical applications, i.e. in the mouth environment. At the open circuit potential, the $\mathrm{Ni}-\mathrm{Cr}$ alloy exhibited impedance values at the order of $10^{5}-10^{6} \mathrm{Ohm} \cdot \mathrm{cm}^{2}$ that shows high corrosion resistance. The corresponding phase shift plot exhibited high capacitive behaviour. However, at $300 \mathrm{mV}$, the impedance decreased to a greater extent which is indicative of defective passive film on the alloy surface. The phase angle plot revealed two time constants.

\section{Discussion}

Nucleation and growth are the two major mechanisms leading to the final structure of a solidifying metal. The final grain structure depends on the ratio of the temperature gradient in the liquid to the rate of advancement of the solid-liquid interface. For most alloys it is impracticable to avoid constitutional undercooling and so dendritic solidification occurs during the production of almost all alloys (Doherty et al 1973). It seems from figure 1 that the extent of segregation of the Ni-rich phases was lowest in vacuum pressure cast alloy and highest in high frequency induction cast alloy. The $\mathrm{Co}-\mathrm{Cr}$ alloy investigated in this study also revealed typical dendritic microstructure (not shown here). However, our EDS analysis showed that the chemical composition of the dendrite and interdendritic regions were close and there was no preferential segregation of $\mathrm{Cr}$ and Mo depleted zones similar to what was observed in $\mathrm{Ni}-\mathrm{Cr}$ alloy.

The results of the electrochemical experiments indicate that the dependence of corrosion resistance of $\mathrm{Ni}-\mathrm{Cr}$ and $\mathrm{Co}-\mathrm{Cr}$ alloys to the microstructural variation associated with the casting methods was marginal. Mulders et al (1996) reported that casting processes had no significant effect on the corrosion resistance of palladium based alloys. The cyclic polarization plots of the present study showed that there was no localized corrosion in the case of $\mathrm{Co}-\mathrm{Cr}$ base alloy. It should be noted that the two alloys differ in their $\mathrm{Cr}$ content. However, similar to the present result, reported works also showed that commercial $\mathrm{Co}-\mathrm{Cr}$ alloys possess more desirable corrosion resistance properties than $\mathrm{Ni}-\mathrm{Cr}$ counterparts. According to Khamis and Seddik (1995), Wirolloy corroded 26 times faster than Wironit alloy. The ion release study on commercially available $\mathrm{Ni}-\mathrm{Cr}-\mathrm{Mo}$ and $\mathrm{Co}-\mathrm{Cr}-\mathrm{Mo}$ casting alloys in lactated sodium chloride solution has shown that $\mathrm{Ni}-\mathrm{Cr}-\mathrm{Mo}$ alloys are more susceptible to corrosion (Gerstorfer et al 1991). Corrosion of $\mathrm{Ni}-\mathrm{Cr}$ alloys occurred through selective dissolution of nickel rich regions (Roach et al 2000; de De Micheli and Riesgo 1982). It is apparent from the present results that the $\mathrm{Ni}-\mathrm{Cr}$ alloy investigated in this study should be considered unsafe as dissolution of nickel rich phases occurred.

Small amount of beryllium is often added to $\mathrm{Ni}-\mathrm{Cr}$ alloys to improve their castability. Be acts as a grain refiner and hardener and enhances the adhesion to the veneering ceramics (Goff et al 1998). It was reported that $\mathrm{Be}$-containing $\mathrm{Ni}-\mathrm{Cr}$ alloys were less resistant to accelerated corrosion (Bumgardner and Lucas 1993; Pan et al 1995; Goff et al 1998). Preferential segregation of Be was found in $\mathrm{Ni}-\mathrm{Cr}$ alloys at areas low in $\mathrm{Cr}$ and $\mathrm{O}$ and these $\mathrm{Cr}$-depleted $\mathrm{NiBe}$ eutectic phases were suggested to be the reason for the decreased corrosion resistance (Bumgardner and Lucas 1993). The small atomic radius of Be element facilitated early Be migration to the surface, resulting in $\mathrm{Cr}$ and Mo depleted areas (Huang 2003). However, the EDS analysis (figure 2) of the present study has not revealed the possible Be segregation as elemental beryllium (atomic number 4) could not be detected using EDS.

The corrosion resistance of $\mathrm{Ni}-\mathrm{Cr}$ and $\mathrm{Co}-\mathrm{Cr}$ alloys varies with their chemical compositions and homogeneity of the passive film formed. Differences in microstructure can influence the initial growth, compactness and compositional homogeneity of a passive film (Liu et al 2007). A higher percentage of $\mathrm{Cr}_{2} \mathrm{O}_{3}$ and $\mathrm{MoO}_{3}$ in the passive film could lead to a higher resistance to metal ion transfer through the passive film. When compared to $\mathrm{Cr}_{2} \mathrm{O}_{3}$, the oxide of nickel is more porous and has less protective ability to corrosion. Hence, the zones of passive film rich in $\mathrm{NiO}$ will act as weak regions for localized corrosion and cause localized dissolution of nickel rich phases.

\section{Conclusions}

Pitting corrosion in a Ni-Cr-Mo dental alloy, fabricated by three different casting methods was studied. From the experimental results, the following conclusions were made.

(I) Variation in casting morphologies with casting methods has only marginal influence in the overall corrosion resistance of $\mathrm{Ni}-\mathrm{Cr}$ and $\mathrm{Co}-\mathrm{Cr}$ dental cast alloys.

(II) There was preferential dissolution of $\mathrm{Ni}$ rich, $\mathrm{Cr}$ and Mo depleted zones from the $\mathrm{Ni}-\mathrm{Cr}$ alloy.

(III) The preferential dissolution occurred at a potential of $\sim 150 \mathrm{mV}$.

(IV) The overall corrosion resistance property of the Co$\mathrm{Cr}$ alloy was better than that of the $\mathrm{Ni}-\mathrm{Cr}$ alloy.

\section{Acknowledgement}

This work was supported by second stage of Brain Korea 21 programme, College of Dentistry, Chosun University, Korea.

\section{References}

Bumgardner J D and Lucas L C 1993 Dent. Mater. 9252

Bumgardner J D and Lucas L C 1995 J. Dent. Res. 741521

Cohen S M, Kakar A, Vaidynathan T K and Viswanathan T 1996 J. Prosth. Dent. 76125

de De Micheli S M and Riesgo O 1982 Biomaterials 3209 
Doherty R D, Feest E A and Holm K 1973 Metall. Trans. 4115 Gerstorfer G J, Sauer K H and Passler K 1991 Inter. J. Prosth. 4152

Goff A H L, Joiret S and Abourazzouk D 1998 Electrochim. Acta 4353

Hildebrand H F, Veron C and Martin P 1989 Biomaterials 10545

Huang H H 2003 Biomaterials 241575

Joias R M, Tango R N, de Araujo J E J, de Araujo M A J, Saavedra G S F A, Pees-Junior T J A and Kimpara E T 2008 J. Prosth. Dent. 9955

Khamis E and Seddik M 1995 Inter. Dent. J. 45209

Kim S J, Ko Y M and Choe H C 2007 Adv. Mater. Res. 15/17 164

Liu L, Li Y and Wang F 2007 Electrochim. Acta 527193

Mulders C, Darwish M and Holze R 1996 J. Oral Rehabil. 23 825
Pan J, Gerstorfer J G, Thierry D and Leygraf C 1995 J. Electrochem. Soc. 1421454

Roach M D, Wolan J T, Parsell D E and Bumgardner J D 2000 J. Prosth. Dent. 84623

Rosen E M and Silverman D C 1992 Corrosion 48734

Saji V S and Choe H C 2009 Trans. Nonferrous Met. Soc. China 19785

Schmalz G and Garhammer P 2002 Dent. Mater. 18396

Viennot S, Lissac M, Malquarti G, Dalard F and Grosgogeat B 2006 Acta Biomater. 2321

Wataha J C 2000 J. Prosth. Dent. 83223

Wataha J C, O'dell N L, Singh B B, Ghazi M, Whiteford G M and Lockwood P E 2001 J. Biomed. Mater. Res. 58537

Wylie C M, Shelton R M, Fleming G J and Davenport A J 2007 Dent. Mater. 23714 